\title{
The Invariance as a Feature of Business Systems' Infrastructural Innovative Development
}

\author{
Natalya Kalenskaya \\ Kazan (Volga Region) Federal University, Kazan 420111, Russia \\ Email address: followaida@gmail.com \\ Anna Shafigullina \\ Kazan (Volga Region) Federal University, Kazan 420111, Russia
}

Doi:10.5901/mjss.2014.v5n18p241

\begin{abstract}
The article reveals the notion of "invariance" and enables the invariance model application within the formation of infrastructural security of innovative development. Furthermore, it uncovers the nature of compensatory mechanism of infrastructural security of innovative development formation.
\end{abstract}

Keywords: Invariance, Infrastructure, Infrastructural element, Infrastructural security, Infrastructural resource, Compensatory mechanism.

\section{Introduction}

The infrastructure research methodology was formed in frames of evolutionary approach. At that time the theory of infrastructure was developing within business systems advance provided by functional and industrial approaches. Russian researchers Aleksandrov Y.L., Ignatiev A.M., Sidorovich A.V. state that according to the latter, infrastructure is a set of industries that allow core production to function effectively. In our opinion, this approach views infrastructure beyond economy system. Thus it does not specify the infrastructural influence on economic systems' efficiency. Formed in the framework of reproduction aspect, the functional approach defines infrastructure as a set of material and technical objects that provide conditions necessary for business structures' formation and efficiency (works by McConnel K., Bru S., Kholosov V.G., Russkova E. G. and others). Therefore we do not consider this approach to cover exogenous conditions of infrastructure formation. The category of "innovative infrastructure" springs from scientific theories of innovative development research (the evolutionary theory of innovations, the economic cycle theory, and quantitative approach). Described as part of innovative system, the innovative infrastructure fails to reason endogenous relations within infrastructural elements. The latter create the infrastructure of industrial enterprises innovative development. Large number of infrastructural security research areas (systematic, complex, structural and functional approaches) regard infrastructure as a static complex of interrelated elements. Ways to achieve statics, constancy (i.e. invariance) are neglected, though.

Different sciences view the invariance as the stability and regularity that maintain set characteristics and relations unchanged (Bagautdinova N.G, Goncharova I.V., Shurkina E.Y., Sarkin A.V., Averyanov B.A. Svirina A.A., 2013).

The basic forms of the sustainability theory are as follows:

- an absolute sustainability, achieved through the lack of fixed course deviations;

- a potential sustainability, associated with the socio-economic system development. This form predetermines the extent of the systems' adaptiveness to the unstable exogenous conditions;

- an actual sustainability, which is achieved within the expired period and caused by active factors of the productive-economic potential implementation on the given level. 


\section{Literature Review and Hypothesis}

\subsection{Theoretical Overview}

The "HDS theory" (Hypercomplex Dynamic Systems) and the systemacity as its keystone, form the basis of invariant modeling.

The key property of invariance is encoded in the term itself, i.e. it remains unchanged when exposed to various forces generated by unstable external factors. Derived from "buttress", the basis of invariance conveys engrained traditions, origin and base.

In the frames of systems' theory research, we may note that invariant systems are defined as systems that "change their behavior but, nonetheless, remain within stability area, even exposed to external environment". In our opinion, conceptually, the abovementioned property does not run in contrary with the classical definition of "stability". One may oppose the stability definition as ever constant, invariant process established on certain level.

According to Radionova L.N. and Abdullin L.R., the systems' optimal state is achieved when faced with the optimal extent of management control. It keeps system within the stability area for a long period of time (Radionova L.N., Abdullin L.R., 2007).

Within the systematic approach, the majority of researchers suggest that the stable development requires stable environment, which is impossible by itself. From our point of view, the mechanism of infrastructural security is to settle the issue and provide partial system adaptation to external environment changes

\subsection{Economic and Prognostic Approach}

The economic approach outlines the production and economic activity's orientation on the rationalization of infrastructural security. The stable model is formed on the basis of the theory of the total income maximum flow introduced by Hicks and Lindahl (Hicks J.R., 1939, 2nd ed. 1946). The infrastructural elements activity analysis shows, however, that the main income flow remains unachieved (Lindahl E., 1939). That is why we challenge the theory by Hicks and Lindahl to be the basic effectiveness model.

We suppose that the establishment of the infrastructure of industrial enterprises innovative development is not a spontaneous process. It is susceptible to endo- and exogenous conditions that form the infrastructural security of enterprises' innovative development.

Within the prognostic approach, it is reasonable to study conception of the invariance model itself, the ultimate result and the conditions.

We assume that modeling of infrastructural elements and institutions gives rise to the invariance of the infrastructural security. The invariance is achieved when all / certain infrastructural elements' resources are applied to and all / certain institutions of innovative development and infrastructural security are activated.

We shall arrange 3 groups according to the way the involved resources are optimally correlated.

1. The resource's allocation model that determines the involvement proportions and criteria.

2. The involvement aimed at the search of more favourable terms.

3. The constitutionalism theory, which treats economic development with regard to the appropriate institutional measures taken to provide its effectiveness. Should the measures be effective, the transactional costs reduce and the infrastructural security effectiveness is attained, respectively.

According to Tsyrenova E. [4], the stable development researches on mesolevel are rarely undertaken and the institutions mechanisms that influence further balanced mesosystems' transformations require thorough study. We share this point of view and consider the detailed research on the mechanism of the institutional impact on the infrastructural development formation to be necessary.

The specificity of infrastructural security institutional relations allows the modeling of any given element's participation extent. Meanwhile the model remains unchanged. By means of the introduced structural-functional model of infrastructural security we structured its elements according to the domineering institutions.

The formalized invariant model is represented as an infrastructural development model (lir), which comprises technologies transfer, support environment's and institutions' elements.

Thus, we suggest the formula of infrastructural security:

I ir $=\{E T T ; E S E ;$ IIS $\}$

"The basic architecture" model presupposes several infrastructural elements (network structures) and institutions. This generates formulas 2-4. 
$\mathrm{ETT}=\left\{\mathrm{ETT}_{1}, \mathrm{ETT}_{2}, \ldots \mathrm{ETT}\right.$ \} $;$

$E S E=\left\{\mathrm{ESE}_{1}, \mathrm{ESE}_{2}, \ldots \mathrm{ESE}_{n}\right\}$;

$\| S=\left\{I I S_{1},\left\|S_{2}, \ldots\right\| S_{n}\right\}$.

"The fragmentary participation" model includes a part of infrastructural elements and institutes (formulas 5-7):

$\mathrm{ETT}=\left\{\mathrm{ETT}_{1}, \mathrm{ETT}_{2}, \mathrm{ETT}_{3}\right\}$;

$\mathrm{ESE}=\left\{\mathrm{ESE}_{1}, \mathrm{ESE}_{2}, \mathrm{ESE}_{3}\right\}$

$\| \mathrm{S}=\left\{I I T_{1}, I T_{2}, I I T_{3}\right\}$.

Table 1. Types characteristics of the infrastructural security of industrial enterprises' innovative development

\begin{tabular}{|c|c|c|c|c|}
\hline Model types & $\begin{array}{c}\text { Innovative development } \\
\text { security }\end{array}$ & $\begin{array}{c}\text { The core of the infrastructural } \\
\text { security mechanism }\end{array}$ & $\begin{array}{c}\text { The compensatory } \\
\text { mechanism }\end{array}$ & $\begin{array}{c}\text { The infrastructural } \\
\text { security effectiveness }\end{array}$ \\
\hline "The basic & $\begin{array}{c}\text { The resources of all } \\
\text { infrastructural elements of } \\
\text { architecture" }\end{array}$ & $\begin{array}{c}\text { The infrastructural } \\
\text { agglomeration formation }\end{array}$ & $\begin{array}{c}\text { The infrastructural elements } \\
\text { compensate the } \\
\text { infrastructural security } \\
\text { transactional (TAC) and }\end{array}$ & $\begin{array}{c}\text { The infrastructural } \\
\text { resources generation }\end{array}$ \\
\cline { 1 - 2 } $\begin{array}{c}\text { "The fragmentary } \\
\text { participation" }\end{array}$ & $\begin{array}{c}\text { The resources of a part of } \\
\text { elements }\end{array}$ & $\begin{array}{c}\text { The infrastructural division } \\
\text { formation }\end{array}$ & $\begin{array}{c}\text { The infrastructural } \\
\text { resources localization }\end{array}$ \\
\hline
\end{tabular}

In the frames of the invariance model of infrastructural security functions we distinguish between following architecture types:

1) "The basic architecture" - all infrastructural elements and institutions involved;

2) "The fragmentary participation" - a part of infrastructural elements and institutes involved.

The choice criterion is the infrastructural resources' involvement.

It should be emphasized that the type choice is predetermined by the compensatory mechanism, which implies following correlations:

- internal economy which partially compensates infrastructural resources;

- economy of localization (external for the enterprises, but internal for infrastructural elements). The advantage is that the effective development of the industry (and economic system, accordingly) largely depends on the specialization level and the effectiveness of industrial enterprise. The infrastructural security provides the latter by means of resources localization or integration;

- mesolevel economy. The infrastructural security facilitates the interaction of all economic agents within transactional costs.

When forming the model one needs to reveal and consider contradictions that are inevitably associated with innovative development. We share statement proposed by Fonotov A.V. He defines contradictions as [5]: "... the interaction of the set of mutually exclusive but interrelated ideas, conceptions, interests, factors and methods that either stimulate its growth and effectiveness (when correspond to the development unbiased logic) or decelerate it, cause crisis, deform technological development".

The most acute contradictions (in theory and in practice) include [6]:

- the contradictions between the interests of infrastructural security participants;

- the contradictions between innovative development institutions;

- the contradictions between speed and scale of industrial and infrastructural complexes.

We formed the model of infrastructural security of innovative development. It is aimed at:

- technological modernization, which changes set of tools that handle the issue of infrastructural security;

- social modernization, which modifies society's professional, social and educational structures meeting the demands of technological modernization;

- institutional modernization, which changes economic and legal mechanisms of innovative development regulation according to the technological and social modernization demands.

The invariance model security is provided by the infrastructural resources involved. The researches by Gluhov V.V., Kolosov B.G., and Yun O.M. [7] prove the general limited resource to be equally shared by the direct productive activity of the enterprise itself and the infrastructure. The statement, however, does not consider external infrastructural security.

Thus, we assume the invariance mechanism of resource allocation to influence the effectiveness of infrastructure's resource security. This marks the types (alternatives) of the infrastructural security within the model we developed.

Within "The basic architecture" type the infrastructural security is realized by means of resources of all 
infrastructural elements that constitute regional innovative system:

\section{$I_{s}=F / Q$}

with $I_{s}$ as infrastructural security; $F$ - finances allocated for the infrastructural security of $(n)$ enterprise's innovative development; Q - quantity of the elements involved.

Within "The fragmentary participation" type the limited resource allocated for the infrastructural security is separately rated for the infrastructural element and enterprise.

$\mathrm{F}=\mathrm{F}_{\mathrm{ie}}+\mathrm{Fe}_{\mathrm{e}}$

with $\mathrm{F}$ as general limited finance of the industrial enterprise and the infrastructural element involved;

$\mathrm{F}_{\mathrm{ie}}$ - the finance allocated by infrastructural element; $\mathrm{Fe}_{\mathrm{e}}$ - the finance allocated by enterprise for the infrastructural security.

The infrastructural security is primarily characterized by the functions' targeted unity and their redistribution causes infrastructure's architecture change. Thus, the infrastructural security architecture is formed by means of infrastructural elements' resources integration. Therefore, the core of the infrastructural security mechanism is determined: all elements activated, the core is infrastructural agglomerate; part of elements activated - infrastructural division.

The core constituting elements are inextricably interrelated. On the one hand, it is manifested in labor, investments, financial and other resources exchange, and on the other, in risks sharing and costs reduction. That is why the systematic monitoring of elements' productivity is to be used in order to provide reasonable application of infrastructure's resource potential. Moreover, it timely detects complexes of organizational economic challenges and amends management and administrative arrangements accordingly. The resource allocation model remains unchanged and proves the infrastructural model to be invari

\section{Methodology}

The methodological approach that we introduce marks the mainline of infrastructural security, i.e. the unity of process and result within innovative development of infrastructural security. According to this, the infrastructural security of industrial enterprises innovative development is a definite, invariant set of functions that contribute to innovative development and maintain it. The functions, however, are governed by the polyfunctional infrastructural security (innovative, institutional, market infrastructures etc.). The domineering institutions predetermine the modeling of infrastructural security elements. Thus, the adaptive architecture of infrastructural security is formed. By architecture we mean a proportion, a correlation between certain elements of infrastructure, that function within integral infrastructural security.

The approach we developed is a means to elicit new quality of infrastructure. It models the architecture of infrastructural elements, thus increasing their efficiency. The quality rests on the following guidelines:

- to create inter-infrastructural effect due to agglomeration of infrastructural security core elements, involved at various stages of innovative processes;

- to form infrastructural mechanism that reduces the gap between science and production;

- to increase institutional effect through the infrastructural security costs reduction / reallocation.

Thus, the methodological approach we developed describes infrastructural security not only as economic subsystem or static system of elements and institutions, but an adaptive model of correlation between infrastructural elements and innovative development institutions.

It is this approach that forms the mechanism to reduce an institutional gap of infrastructural security. It is reached by the integrity of infrastructural elements and institutions that provide industrial enterprises innovative development.

Moreover, the infrastructural security aims to create optimal architecture of elements and institutions and adapt them to industrial features of enterprises. It is to increase synergic effect of correlation between infrastructural elements and industrial enterprises enabled by compensatory mechanism. Resting on neo-institutionalism theory that links infrastructural security with transactional costs efficiency, the methodological approach we developed provides quantitative rating of infrastructural process results. 


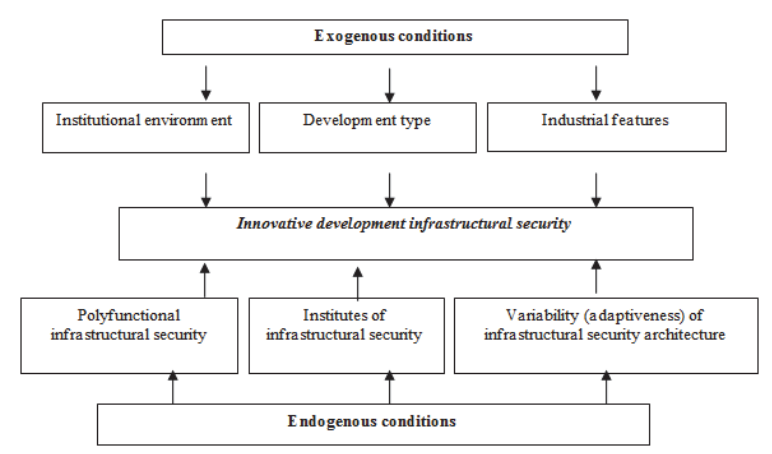

Figure 1. Formation of the innovative development's infrastructure

\section{Conclusions}

It should be noted that the infrastructural division functions in accordance with business systems that seek infrastructural security. As a rule, they comprise small or medium-sized industrial enterprises which account for more than $35 \%$ of innovative products. This predetermines the establishment of institution (network structures) that coordinates stages (production up to realisation) of innovative cycle.

According to the neoinstitutionalism theory, network structures are formed on the basis of infrastructure's key element resources. Thus, applying to the resources, the key element is capable of constructing internal system of industry specified infrastructural elements. It functions as a support environment institution, as well.

In the context of structural and functional aspect, the infrastructural security formation converges the specialized activities (investments, engineering, innovative and technological skills and trainings), as well as supports innovation by means of complementary elements (organizational, legal, informational, communicational and regional structures).

The point to be emphasized is that infrastructural elements are not mutually exclusive; complementarity (furnished by institutional agreements) and interdependence explain their diversity. The innovative relations are carried out either within industrial complex and infrastructural element, or within the latter only. It should be noted that the effectiveness of infrastructural security depends on its continuity for the duration of innovative process.

\section{References}

Carton I.F.S., Schindler F., Yates F., Marsh D. (1972), Progress Toward the Applications of Systems Science Concept to Biology, Army Research Office, Arlington, Va., p.65.

Bagautdinova N.G, Goncharova I.V., Shurkina E.Y., Sarkin A.V., Averyanov B.A. Svirina A.A (2013), Entreprenuerial development in a corrupted environment, Procedia Economic and finance. Volume 4.

Hicks J.R. (1939, 2nd ed. 1946), Value and Capital: An Inquiry into Some Fundamental Principles of Economic Theory. Oxford: Clarendon Press.

Kashbrasiev, R.V., Panasyuk, M.V. (2007) Large and socially significant enterprises as factors of development of regional economy: Case of Tatarstan, Izvestiya Akademii Nauk, Seriya Geograficheskaya(6) , pp. 53-65.

Lindahl E. (1939), Studies in the Theory of Money and Capital, pp. 251-253.

Radionova L.N., Abdullin L.R. (2007), Sustainable development of industrial enterprises, pp. 57-59.

Zheleva S.E., Saktoev V.E., Tsyreneva E.D. (2005), Industrial aspects of socio-economic systems' sustainable development, VSGTU press, p.156. 
